\title{
Public Engagement - Back to Basics
}

\author{
Jennifer Lake, Ec.D.
}

Citizens of a community are 'engaged' when they play an effective role in decision making. That means they are actively involved in defining the issues, identifying solutions, and developing priorities for action and resources. A shift from traditional reins of power and trusting that citizens can and will effectively engage in the issues will likely result in a partnership between local officials and citizens that is nearly always healthy for a community. In most municipalities, public engagement is happening. The fact that it is happening is good but how can it be made more effective? Do local officials want to make it more effective? Do the senior management want the same? Do they have a full understanding of what it is and what it entails?

This paper will qualify the definition, principles and benefits, as well as challenges, of public engagement from a municipal perspective. Best practices from other municipalities will be outlined and details on various levels of engagement and corresponding tools and techniques to employ will be referenced.

Keywords: public engagement, municipality, tools and techniques, best practices

\section{Introduction}

In recent years, public engagement, citizen involvement, and public consultation are topics that are getting more and more attention as municipalities strive for transparency and accountability in the eyes of the public. Understanding fully what public engagement is and what it really means is the first critical step in ensuring it is handled appropriately and meets expectations from public, administrative and political perspectives. Public engagement may seem like a simple initiative of municipal government to ensure that the residents within a municipality are engaged in the decisions that will affect them. However, ensuring tactics are chosen to match expectations is essential and requires skill. There are many benefits of public engagement, but at the same time, there are many challenges that need to be overcome to realize those benefits. Ensuring that public expectations, administrative capabilities, and political will are all aligned and on the same page is critical to meeting public engagement goals. Once all stakeholders have a clear, unified understanding of the depth of public engagement, and have determined their capacities, only then can tactical initiatives be determined and executed. The purpose of this paper is to explore the depth and breadth of public engagement and to help municipalities grasp which approaches or combination of approaches best meet their needs. 


\section{Defining Public Engagement}

Public Engagement is a means through which members of the public become more informed about and/or influence public decision. It can take many forms such as public information/outreach, consultation, participation/deliberation, and sustained public problem solving (Institute for Local Government, 2012g).

Public information or outreach is the kind of public engagement that is characterized by one-way local government communication to residents and other members of the community to inform them about a public problem, issue or policy matter. Examples include information on a web site, in a newsletter, or dispersed through a presentation.

Public Consultation generally includes instances where local officials ask for the individual views or recommendations of residents about public actions and decisions, and where there is generally little or no discussion to add additional knowledge and insight or to promote an exchange of viewpoints. Examples include public hearings, conducting resident surveys or polls or a public meeting that is mainly focused on asking for individual opinions and recommendations about budget decisions.

Public participation or deliberation is the form of engagement through which participants receive new information on a topic and through discussion and deliberation, they jointly prioritize or agree on ideas and/or recommendations intended to inform the decisions of local officials.

The fourth type of public engagement is sustained public problem solving, which is considered to be the deepest form. It typically takes place through the work of place-based committees or task forces, often with multi-sector membership, that over extended periods of time address public problems through collaborative planning, implementation, monitoring and/or assessment.

\section{Benefits}

Making decisions on behalf of an entire community can sometimes make or break a government body, department or figure. In theory, a politician is serving constituents and they are trusting that the best decision is being made on their behalf. Of course, to have all stakeholders happy with a specific decision is not likely to occur as there will always be nay-sayers or a group that will not think the decision is the best one. For a municipal government to be in a position to make the best decision on behalf of the majority of residents, and be confident at decision making time, an effective public engagement plan is key. However, while there are nay-sayers on the outside, there may also be nay-sayers within the administration who perceive engagement as likely to "open up a can of worms" or feel that nothing will get accomplished as not everyone will agree.

Cities and counties throughout California are applying a variety of public engagement strategies and approaches to address issues ranging from land use and budgeting to climate change and 
public safety. They are discovering a number of benefits that can result from the successful engagement of their residents in local decision making (Institute for Local Government, 2012h). The Institute for Local Government cites eight outcomes of why a municipality should engage the public.

1. Better identification of the public's values, ideas and recommendations Elections help identify voter preferences, and communication with individual constituents provides additional information to local officials about resident views on various topics. Good public engagement can provide more nuanced and collective views about an issue by a broader spectrum of residents;

2. More informed residents about issues and about local agencies - Most residents do not regularly follow local policy matters carefully. Good public engagement can present opportunities for residents to better understand an issue and its impacts and to see local challenges as their own challenges as well;

3. Improved local municipality decision-making and actions with better impacts and outcomes - Members of the public have information about their community's history and needs. They also have a sense of the kind of place where they and their families want to live. They can add new voices and new ideas to enrich thinking and planning on topics that concern them. This kind of knowledge, integrated appropriately into local decision making, helps ensure that public decisions are optimal for the community and fit current conditions and needs;

4. More community buy-in and support, with less contentiousness - Participation helps generate ownership. Involved residents who have helped shape a proposed policy, project or program will better understand the issue itself and the reasons for the decisions that are made. Good communications about the public's involvement with a local decision can increase the support of the broader community as well;

5. More civil discussions and decision making - Earlier, informed, and facilitated deliberation by residents will frequently offer a better chance for more civil and reasoned conversations and problem solving than public hearing and other less collaborative opportunities for public input;

6. Faster project implementation with less need to revisit again - Making public decisions is one thing; successfully implementing these decisions is often something else altogether. Good public engagement reduces the need for unnecessary decision-making "do-overs";

7. More trust in each other and in the municipality - People who work together on common problems usually have more appreciation of the problem and of each other. Many forms of public engagement provide opportunity to get behind peoples' statements and understand the reasons for what they think and say. This helps enhance understanding and respect among participants. It also inspires 
confidence that problems can be solved - which promotes more cooperation over time;

8. Higher rates of community participation and leadership development - Engaging the public in new ways offers additional opportunities for people to take part in the civic and political life of their community. This may include community members who have traditionally participated less than others. Engagement offers avenues for not only contributing to local decisions but for residents to gain knowledge, experience and confidence in the workings of their local government. Those engaged may become future neighbourhood volunteers, civic and community leaders, and elected officials who will be more prepared, qualified, informed and involved citizens.

\section{Challenges}

While many municipalities will generally agree that they engage the public on a regular basis, the extent and consistency to which engagement occurs is likely varied. In Rural Pennsylvania, most citizens do not participate in the decisions that affect their daily lives, and there is often a lack of trust between citizens and local officials (Bassler, Brasier, Fogle \& Taverno, 2008). If municipal leaders worldwide were polled, surely they would all agree that significant gaps and barriers exist to effective public engagement with the more common challenges including:

1. Lack of a Public Engagement Strategy to execute consistently;

2. Lack of resources, both human and financial;

3. Lack of technical skill and know-how to truly commit to the process;

4. Concerns about control and management of the process;

5. Lack of understanding of the benefits and consequences if poorly executed;

6. The need to get public engagement right the first time.

\section{Strategies}

A crucial bridge over these challenges is the use of appropriate strategies and tools to encourage citizens and local officials to interact regularly, increase their knowledge of each other, and build trust. A more engaged citizenry can lead to better organizational decisions, more effective resource allocation, reduced conflict, and enhanced quality of life for community residents. Getting all the pieces in place to get citizens involved and make their experiences positive can be daunting, take considerable time and resources, and can involve significant organizational risk. The following is a selection of recommended strategies to be used in public engagement from a variety of reports on the topic.

1. Take the time to understand the reasons for and extent of concerns. To appropriately and proactively address concerns, involve the public in the planning process of projects, ask for and make use of input, and answer questions early and often. Remember that a vocal 
opposition does not necessarily mean a majority opposition. (Great Lakes Wind Collaborative, 2011).

2. Conduct ongoing outreach and engagement to reach broader segments of a community who may not have yet formed an opinion. They may be disinterested or they may be quietly waiting to learn about how the project might impact them.

3. Special efforts must be made to reach out to members of the community who may be less engaged or less vocal in order to assess the true sentiments of a community.

4. Public engagement can mean different things to different people, both internally within the organization and externally among the public. In order to ensure a successful public engagement strategy, politicians and senior management need to establish a single vision for public engagement and must all buy in to the chosen principles and tactics. Furthermore, the public must be informed of the strategy and also buy into its direction. Trust needs to be built early (Barnes \& Mann, 2009).

5. It takes the whole community to create and sustain a truly effective democratic governance culture. Many municipal officials report that important players (including those in their own organizations) are not stepping up to their proper roles (Barnes \& Mann, 2009). It is essential that roles for all stakeholders are clearly defined and that a municipality regards public engagement as a core responsibility for processes to be truly effective.

6. While there may be an understanding of what public engagement is, there may be differing opinions on what makes public engagement effective. Politicians might say it is most important for people to have the right information and that this discussion is civil. This might contrast with criteria that others identify. Effective public engagement requires skill. Municipalities should either train select internal staff, or retain a consultant to facilitate all aspects of public engagement (Barnes \& Mann, 2009).

7. Effective public engagement needs to be meaningful to its participants. They need to believe that the exercise is being undertaken in good faith and they should not feel that the community is "just going through the motions". When focus groups were conducted with citizens from Fort Saskatchewan in June 2011 (The Praxis Group, 2012), they said that public engagement needed to:

- Inspire enthusiasm and passion to get people involved

- Demonstrate to citizens that their feedback and opinions matter

- Indicate how the information collected will be used

- Share information from the small group discussions with a wider audience

- Show participants that their input has been heard

- Indicate why and how decisions are reached

- Include a range of opinions and perspectives

- Change direction if the community points in that way

- Use multiple approaches

- Make people feel it is important and meaningful for them to be involved. 
Ensuring all of the points noted above is in itself challenging, but the extra effort to get it right the first time will be invaluable. When public engagement involves two-way communication, it offers benefits to both the community and the public. However, to be successful, there must be both a genuine commitment to providing an open and transparent public engagement, and a demonstrated link between engagement and decision making.

\section{Spectrums of Public Participation}

The International Association for Public Participation (IAP2) - the preeminent international organization advancing the practice of public participation - defines public participation as a means to involve those who are affected by a decision in the decision-making process. It advocates for providing participants with the information they need to be involved in a meaningful way, and it communicates to participants how their input affects the decision (International Association for Public Participation, 1996).

There are many formulations and spectrums available for the level of public engagement that a municipality can embrace. A widely used tool designed by the IAP2 is called the Public Participation Spectrum (see Figure 1) (Block, 2012).

This spectrum is an excellent tool for determining the level of engagement the municipality can manage given its capacity and access to resources. Finding a balance between capacity, management and public expectation will always be the main challenge. The public has a right to comment on decisions that affect their lives, and yet, decision makers control their degree of involvement. In order to determine the degree of involvement, the organization should determine what decision needs to be made; how the decision is made and who makes the decision; how the decision will affect the public; and what members of the public the decision will affect. This information will help determine their goal for participation and the resulting promise to the public. The tool provides several examples of techniques that could be used on each level of the spectrum.

It is important to note that this spectrum can be referenced as part of an overall engagement plan or used each time an issue or project will have an impact on the public. A variety of tactics may be suitable or required for varying topics. Whenever public engagement is being considered, it is essential for administration and council to understand the underlying principles are understood and taken into consideration along with the previously outlined benefits and challenges. 
Figure 1: IAP2 Public Participation Spectrum

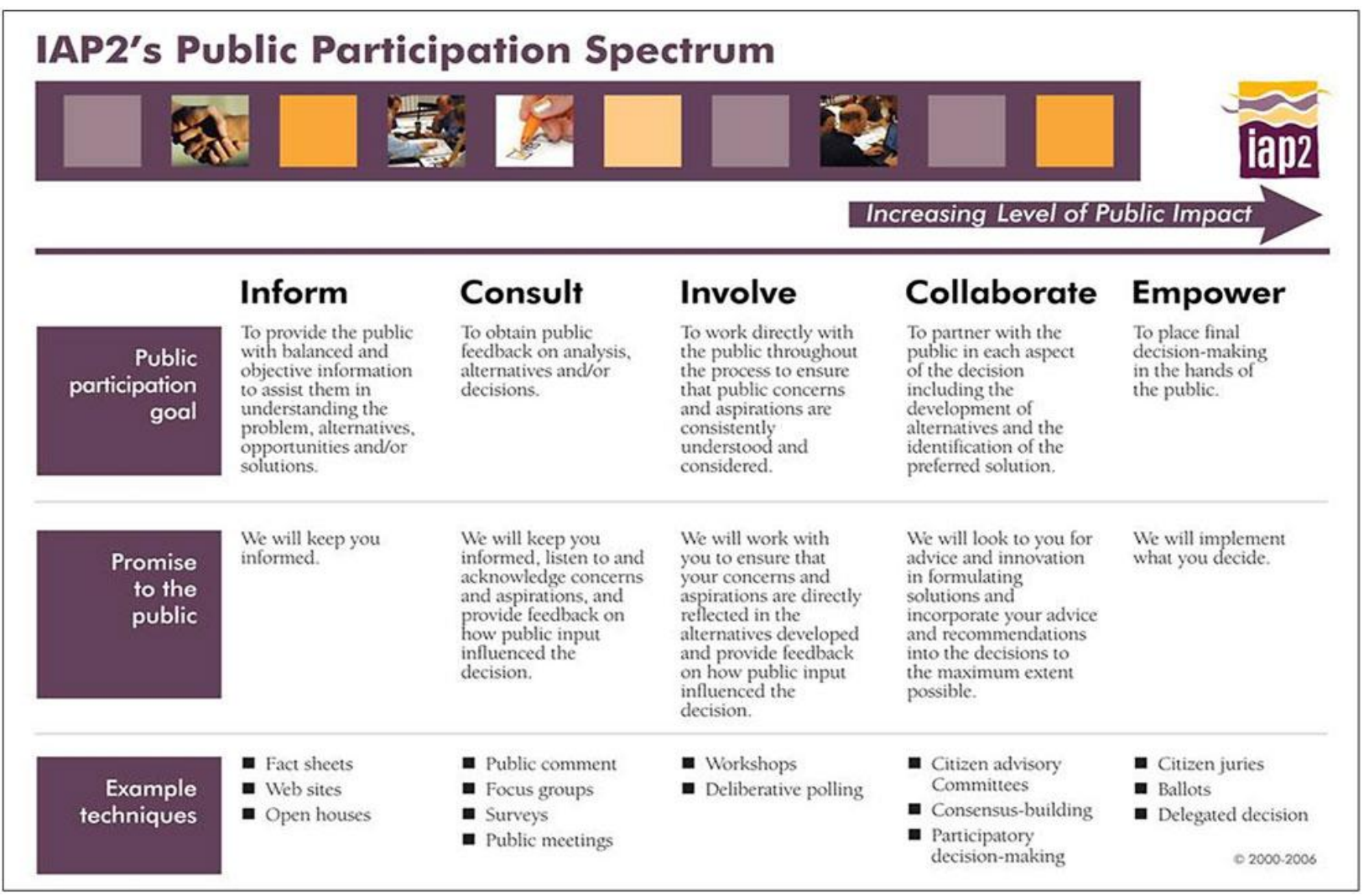

The City of Fort Saskatchewan commissioned the Praxis Group to assist them with the development of a public engagement framework. This framework is intended to provide elected officials and public servants with a common basis for understanding and approaching public engagement (The Praxis Group, 2012). The Praxis Group outline Tools and Techniques organized by the level of public engagement that the tool or technique will provide as outlined in Figure 1 earlier in this paper.

At the basic level, the public is informed about a project or activity. The level is characterized by one-way communication and typically involves the distribution of information aimed at raising awareness and understanding. In this case, the public is least likely to influence decision making as the information is dispensed via print material, paid advertising, electronic media, news releases, press conferences, static displays, and public service announcements.

At the next level, communication becomes two-way and information is shared with the public and opportunities for feedback are provided. The intent is to raise awareness and understanding about a project or activity and to receive and consider public comments. At this stage, the City and the public have the opportunity to listen and to learn about each other's plans, views, issues and expectations. Examples of tools include open houses, public meetings, surveys, polls, 
presentations, interviews, small group meetings, focus groups, community events and expert panels.

At the involvement level, the two-way communication increases and centers on established and mutually accepted objectives. At this level, the public has more influence on decision-making, and feedback from the public is analyzed and incorporated into alternatives and outcomes. Examples include workshops and roundtables.

Moving through the continuum, the final level is collaboration. This level is characterized by joint planning and shared decision-making. Here the public participates in the analysis of issues, contributes to the development of alternatives and directly influences recommendations, decisions and outcomes. Tactical examples include advisory committees, task forces, study circles and third party facilitation.

The Praxis Group research, which includes a useful outline of these tools and techniques accompanied by tips, benefits and risks, can be consulted for further assistance when determining appropriate tools (The Praxis Group, 2012).

\section{Principles of Public Engagement}

The Institute for Local Government's Public Engagement Program (Institute for Local Government, 2012e) have developed ten principles to serve as helpful indicators of effective and ethical public engagement practice by local agencies (See Figure 2). These principles will help guide municipalities, schools, or other groups in the design of public engagement processes and strategies.

Figure 2: Principles of Public Engagement

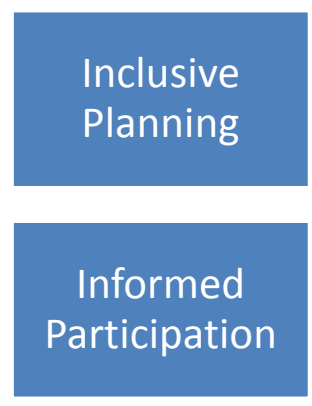

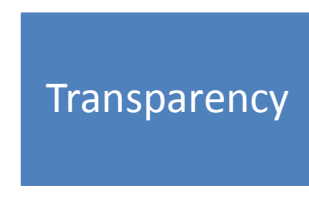

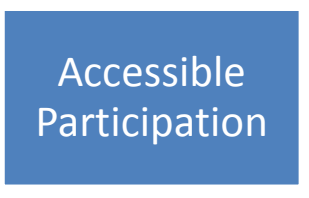

Feedback to Participants
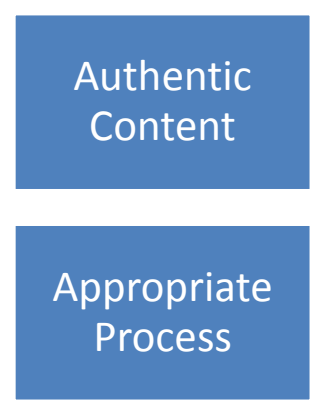

Authentic Use of Information Recieved

Breadth of

Participation
Evaluation 
The principles outlined in Figure 2 and detailed below can serve to guide trusted, high-quality and effective public engagement efforts that are sponsored, designed, convened and/or facilitated by local public officials (Institute for Local Development, 2012a).

1. Inclusive Planning - The planning and design of a public engagement process includes input from appropriate local officials as well as from members of intended participant communities.

2. Transparency - There is clarity and transparency about public engagement process sponsorship, purpose, design, and how decision makers will use the process results.

3. Authentic Intent - A primary purpose of the public engagement process is to generate public views and ideas to help shape local government action or policy, rather than persuade residents to accept a decision that has already been made.

4. Breadth of Participation - The public engagement process includes people and viewpoints that are broadly reflective of the local agency's population of affected residents.

5. Informed Participation - Participants in the public engagement process have information and/or access to expertise consistent with the work that sponsors and convenors ask them to do.

6. Accessible Participation - Public engagement processes are broadly accessible in terms of location, time, and language, and support the engagement of residents with disabilities.

7. Appropriate Process - The public engagement process utilizes one or more discussion formats that are responsive to the needs of identified participant groups, and encourages full, authentic, effective and equitable participation consistent with process purposes. This may include relationships with existing community forums.

8. Authentic Use of Information Received - The ideas, preferences and/or recommendations contributed by the public are documented and seriously considered by decision makers.

9. Feedback to Participants - Local officials communicate ultimate decisions back to process participants and the boarder public, with a description of how the public input was considered and used.

10. Evaluation - Sponsors and participants evaluate each public engagement process with the collected feedback and learning shared broadly and applied to future engagement efforts.

Two leading organizations of public engagement practitioners, the National Coalition for Dialogue and Deliberation (NCDD) and the International Association for Public Participation have each developed principles, or values, to help guide general practice in this field. NCDD's mission is to bring together and support people, organizations, and resources in ways that expand the power of discussion to benefit society. Their primary purpose is to educate on dialogue and deliberation by serving as a resource clearinghouse, a news source, a gathering place, and a 
facilitative leader for the dialogue and deliberation community and beyond. The International Association for Public Participation is an international association of members who seek to promote and improve the practice of public participation in relation to individuals, governments, institutions, and other entities that affect the public interest in nations throughout the world. In recent years, the association has continued its growth and established itself as a leader in the field. Any practitioner who is working on any aspect of public engagement should review the work of these associations for resource information and guidance.

\section{Best Practices}

There are many instances of what is working with municipalities in the area of public engagement. We have learned that levels of engagement vary and tactics are vast. We have also determined that there are many benefits, challenges and conceptions of effective public engagement from region to region, politician to politician and staffer to staffer. Discussions must be had and decisions must be made using the $5 \mathrm{~W}$ 's - who, what, when, where, why, as well as how-before any public engagement can effectively take place.

In the summer of 2009, the National League of Cities, Centre for Research and Innovation conducted a survey of municipal officials, both elected and managerial, to find out more about their views, attitudes and local practices in public engagement. The results are detailed in their report, "Making Local Democracy Work: Municipal Officials' Views about Public Engagement" (Barnes \& Mann, 2009). The survey yielded a wealth of information about the ways city officials understand and approach public engagement. Observations from their findings are outlined as follows:

- $\quad$ Place matters... and places are different;

- $\quad$ Public Engagement means different things to different people;

- It takes a village to do effective public engagement;

- Municipal officials and other stakeholders have different ideas about what makes public engagement effective;

- Municipal officials are ambivalent on this topic;

- Municipal officials and residents need skills to do this work well.

Most often when consultants are engaged in studies to find answers, the result is more questions and recommended follow up. The authors' insights for further research are outlined at the end of the report and include questions such as why do officials use public engagement on some topics and not others, what is the nature and impact of planning for public engagement, and what do municipal officials find useful about public engagement? The report is a great starting point for municipalities looking to develop policies and procedures around public engagement and the survey is a good start point for internal discussion.

\section{Examples of good public engagement}


Golden, BC undertook a large public engagement process on the community's Official Community Plan (Davis, 2010). Instead of hiring a consultant or training staff, the Town hired two co-op students from the College of the Rockies and they were given "free reign" to design and implement an engagement strategy. The students were cheerful and approachable and went out into the community to engage citizens; they set up big signs and did public engagement in grocery stores, coffee shops, public skate events and jam nights at a local pub. Their efforts were very successful. The Golden example shows that by embracing new ways to engage the public (and youth) and establishing a culture of trust, the community will more likely buy-in to the plan. A year after Golden's Official Community Plan was adopted, it won the 2009 UBCM Innovation and Leadership award for small communities.

Revelstoke, BC completed a new Official Community Plan in July 2009. Leading up to the plan's development, eight neighbourhood groups met monthly with planning staff to raise their concerns, and these meetings continue on an ongoing basis. This form of ongoing engagement at the neighbourhood level helps increase social capital in the community for both the City and residents. The groups are also a means for the City to get messaging out on neighbourhood level. Since the engagement process in 2009 , Revelstoke is now a recognized leader in social planning, community energy development and early childhood development (Davis, 2010).

Williams Lake, BC has undertaken a community-centred sustainability plan that involved a number of creative engagement strategies. They kicked off their plan with a public event called Performance in the Park where hundreds of residents came out to watch live music and had a chance to win a prize for participating in stations for the nine draft priority areas. Another method employed was organizing kitchen table meetings where a volunteer "host" invited friends to come and discuss the priority areas over the kitchen table. Using social connections, members of the project team invited friends and acquaintances from diverse community organizations to a 'conversation café' style meeting. Additionally, the municipality identified 'hot spot' areas of the town where the public would frequent and set up displays where they could become educated on a project and jot down their thoughts on a table top (Davis, 2010).

\section{Conclusion}

Citizens of a community are 'engaged' when they play an effective role in decision making. That means they are actively involved in defining the issues, identifying solutions, and developing priorities for action and resources. A shift from traditional reins of power and trusting that citizens can and will effectively engage in the issues will likely result in a partnership between local officials and citizens that is nearly always healthy for a community. In most municipalities, public engagement is happening. The fact that it is happening is good, but it needs to be more effective.

Based on the information provided above, the first step is to determine if local officials and senior management want to make public engagement more effective. The next is to determine if 
they have a full understanding of what it is and what it entails. An excellent way to find out is by polling internal stakeholders to assess their level of understanding and interest when it comes to public engagement. The survey used by the National League of Cities is an excellent starting point (Barnes \& Mann 2009).

Before the decision is made about the level of engagement, it is important to be clear about the main purpose. Is it to inform, gather information and views, discuss through two-way dialogue, collaborate in making a decision about a complex issue, or delegate decision making to interest groups or the public? Keep in mind that the level of engagement may vary depending on the nature of the public, particularly if there are many different stakeholders. For example, it may be appropriate to simply inform geographically distant stakeholders that a project will be undertaken, while those living nearby might be involved in a more collaborative process.

Once stakeholders have an adequate understanding of the project and are united on a purpose and the level of engagement required, then the process of formalizing public engagement within the municipality can begin. Developing a strategy, vision, and communication protocols will eventually lead to identifying specific projects in which to engage the public and determining the tools and techniques that are best to employ. There are many checklists, toolkits and organized associations that are accessible to municipal officials to ensure the process of developing an effective engagement process is as effective as the implementing the process itself.

\section{Bio}

Jennifer Lake is a lifelong resident of Conception Bay South, Newfoundland and Labrador. Jennifer is employed by the Town's Economic Development and Tourism Department and has a Certificate in Economic Development from the University of Waterloo, a Bachelor Degree in Physical Education with a Concentration in Teaching from Memorial University, and in September 2013 was the first economic development professional in the province of Newfoundland and Labrador to receive her Ec.D. Designation from the Economic Developers Association of Canada. Jennifer is currently working towards completing her Fellowship Designation.

\section{References}

Abelson, J., Forest, P.G., Eyles, J., Smith, P., Martin, E. \& Gauvin, F.P (2001, June). Deliberations about Deliberations: Issues in the Design and Evaluation of Public Consultation Processes. McMaster University Centre for Health Economics and Policy Analysis Research Working Paper 01-04.

Barnes, W. \& Mann, B. (2009). Making Local Democracy Work: Municipal Officials' View about Public Engagement. National League of Cities Center for Research and Innovation. 
Bassler, A., Brasier, K., Fogle, N. \& Taverno, R. (2008). Developing Effective Citizen Engagement: A How-To Guide for Community Leaders. Pennsylvania State University Cooperative Extension.

Block, A. (2013). Social Media - A Tool in Public Participation. EDAC/University of Waterloo Year 1 and 2 Paper.

Davis, S. (2010). Moving Sustainability Forward: Public Engagement for Local Government Sustainability Planning in the Columbia Basin Trust Area. Columbia Basin Trust. Retrieved from https://dspace.library.uvic.ca/bitstream/handle/1828/2898/davis_sara.pdf?sequence=1

Diamond Municipal Solutions (2012). Enabling Citizen Engagement in Municipal Government. Diamond Client Summit Presentation, Banff, AB.

FCM International Centre for Municipal Development (2007). Local Government Participatory Practices Manual - A toolkit to support public participation in municipal decision making.

Retrieved from http://www.fcm.ca/Documents/tools/International/Local_Government_Participatory_Practices_ Manual_EN.pdf

Great Lakes Wind Collaborative (2011). Community Support through Public Engagement and Outreach, Best Practice \#7. Best Practices for Sustainable Wind Energy Development in the Great Lakes Region.

Institute for Local Government (2012a). Beyond the Usuals: Ideas to Encourage Broader Public Engagement in Community Decision-making. Retrieved from www.ca-ilg.org/BeyondUsuals.

Institute for Local Government (2012b). Effective Public Engagement through Strategic Communication. Retrieved from www.ca-ilg.org/PEStrategicCommunications.

Institute for Local Government (2012c). Measuring the Success of Local Public Engagement. Retrieved from www.ca-ilg.org/MeasuringPESuccess.

Institute for Local Government (2012d). Planning Public Engagement - Key Questions for Local Officials. Retrieved from www.ca-ilg.org/PublicEngagementKeyQuestions.

Institute for Local Development (2012e). Principles of Public Engagement? Retrieved from www.ca-ilg.org/PublicEngagementPrinciples.

Institute for Local Government (2012f). Three Orientations of Local Government to Public Engagement - Passive, Active, Sustaining. Retrieved from www.ca-ilg.org/PEorientations.

Institute for Local Development (2012g). What is Public Engagement? Retrieved from www.cailg.org/WhatIsPublicEngagement 
Institute for Local Development (2012h). Why Engage the Public? Retrieved from www.cailg.org/WhyEngage

International Association for Public Participation (1996). P2 Practitioner Tools. Retrieved from http://www.iap2.org/?page=A5

Lenihan, D (2012). Rescuing Policy - The Case for Public Engagement. Ottawa, ON: Public Policy Forum.

National Coalition for Dialogue \& Deliberation (n.d). NCDD Resource Centre. Retrieved from http://ncdd.org/rc/

Office of the Auditor General of British Columbia (2008). Public Participation: Principles and Best Practices for British Columbia. Retrieved from https://www.bcauditor.com/online/pubs/394/394

Silveira, K., Shaffer, R. \& Behr, C. (1993). A Summary of Citizen Participation Methods for the Waterfront Development Project in Oconto, Wisconsin. Department of Agricultural Economics, University of Wisconsin-Madison/Extension.

Sheedy, A (2008). Handbook on Citizen Engagement: Beyond Consultation. Canadian Policy Research Networks.

Stephens, M. (2009). Toward Good Practice in Public Engagement - A Participatory Evaluation Guide for CSOs. Canadian Coalition to End Global Poverty.

The Praxis Group (2012). Public Engagement Framework for the City of Fort Saskatchewan. Alberta Municipal Affairs'Collaborative Governance Initiative. 